\title{
Apoptosome-dependent caspase activation proteins as prognostic markers in Stage II and III colorectal cancer
}

\author{
S Hector ${ }^{1,2}$, S Conlon ${ }^{3}$, J Schmid ${ }^{1,2}$, P Dicker ${ }^{4}$, RJ Cummins ${ }^{3}$, CG Concannon ${ }^{1,2}$, PG Johnston ${ }^{5}$, EW Kay ${ }^{3}$ \\ and JHM Prehn ${ }^{*, 1,2}$
}

'Department of Physiology and Medical Physics, Dublin 9, Ireland; ' ${ }^{2}$ Centre for Systems Medicine, Dublin 9, Ireland; ${ }^{3}$ Department of Pathology, Beaumont Hospital, Dublin 9, Ireland; ${ }^{4}$ Division of Population Health Sciences, Royal College of Surgeons in Ireland, 123 Saint Stephen's Green, Dublin 2, Ireland; ${ }^{5}$ Centre for Cancer Research and Cell Biology, Queen's University Belfast, Belfast, Northern Ireland

\begin{abstract}
BACKGROUND: Critical to successful execution of mitochondrial-mediated apoptosis is apoptosome formation and subsequent activation of caspases. Defects in this pathway have an important role in colorectal carcinogenesis and chemoresistance; therefore, the expression of apoptosome-associated proteins may be associated with clinical outcome and response to chemotherapy. METHODS: Here we performed a systematic analysis of the immunohistochemical expression of the key proteins involved in apoptosome-dependent caspase activation (APAFI, Pro-caspases 9 and 3, SMAC, and XIAP) in a cohort of Stage II and III colorectal cancer patients from a Phase III trial of adjuvant 5-fluorouracil-based chemotherapy vs postoperative observation alone.

RESULTS: Survival analysis indicated that of the apoptosome-associated proteins examined here, Pro-caspase 3 and APAFI have potential clinical utility as predictive markers in Stage II and III colorectal cancer, respectively. Interestingly, we identified APAFI staining to be associated with better recurrence-free and overall survival in patients receiving chemotherapy.

CONCLUSION: These studies reveal the importance of the apoptosome-dependent caspase activation pathway, specifically Pro-caspase 3 and APAFI proteins, for predicting both prognosis and response to therapy.

British Journal of Cancer (2012) 106, |499-I505. doi:I0.1038/bjc.2012.133 www.bjcancer.com

Published online 5 April 2012

(c) 2012 Cancer Research UK
\end{abstract}

Keywords: apoptosis; caspases; colorectal cancer; prognosis

Colorectal cancer has among the highest incidence and mortality rates of any cancer in the Western world, with global numbers currently increasing because of ageing populations and an increased prevalence of colorectal cancer incidence in the developing world (Center et al, 2009; Jemal et al, 2011). Owing to its asymptomatic nature, colorectal cancer is frequently diagnosed in its latter stages in which there is local, lymphatic or metastatic disease spread, thereby indicating a need for adjuvant 5-fluorouracil (5-FU)-based chemotherapy. Patients with nodepositive Stage III disease have a known benefit from adjuvant chemotherapy, with response rates at approximately $50 \%$ (de Gramont et al, 2000; Goldberg et al, 2004). However, among node-negative Stage II patients, $80 \%$ will benefit from surgical resection alone (Gray et al, 2007), indicating that only a small portion of these patients will benefit from chemotherapy; however, there are no known effective markers to readily distinguish this subset of patients.

Dysfunctional apoptosis is well recognised as a contributing factor in both malignant progression and the development of chemotherapy resistance in colorectal cancer (Gourdier et al, 2002; Igney and Krammer, 2002; Johnstone et al, 2002). Commonly used chemotherapies in the treatment of cancers of the colon and rectum, such as the DNA-damaging agents 5-FU and oxaliplatin, activate the intrinsic pathway of apoptotic cell death and

*Correspondence: Professor JHM Prehn; E-mail: prehn@rcsi.ie Revised 25 January 2012; accepted 14 March 2012; published online 5 April 2012 subsequent mitochondrial outer membrane permeabilisation (Kaufmann and Earnshaw, 2000; Arango et al, 2004), resulting in the release of cytochrome- $c$ and subsequent apoptosome formation. The apoptosome, a complex of cytochrome- $c$ and APAF-1, recruits and activates the initiator Pro-caspase 9, leading to the activation of the effector caspases, in particular Procaspase 3, culminating in those biochemical and morphological changes associated with apoptotic cell death (Li et al, 1997). This pathway is further regulated by the inhibitor of caspase protein XIAP, which works through the direct inhibition of active caspases 9 and 3 (Deveraux and Reed, 1999) and is also implicated in the ubiquitination of caspases, targeting them for proteasomal degradation (Suzuki et al, 2001; MacFarlane et al, 2002). This pathway is further regulated by the direct interaction between XIAP and its antagonist SMAC (Verhagen et al, 2000).

Because of the importance of this pathway in cancer progression and chemotherapy-induced cell death, apoptosome-associated proteins may be important markers for colorectal cancer prognosis and chemotherapy response. Several studies have examined the immunohistochemical expression of individual proteins associated with apoptosis execution in colorectal cancer (Hector \& Prehn, 2009). Increased expression of APAF1 has been shown to be associated with longer patient survival in rectal cancer patients (Zlobec et al, 2006) and loss of APAF1 has been implicated in tumour progression and more aggressive disease (Paik et al, 2007). Similarly, longer overall survival has been associated with increased SMAC (Endo et al, 2009) and caspase 9 (Strater et al, 2010). The anti-apoptotic XIAP has also been implicated 
as a potential prognostic marker for colorectal cancer, with increased expression correlating with poor patient outcome (Xiang et al, 2009). A singular study examining the prognostic value of caspase 3 protein expression in colorectal cancer did not find any association with patient outcome (De Oliveira Lima et al, 2009). However, no study to date has provided a comprehensive analysis of these key regulatory proteins as markersof for colorectal cancer prognosis or chemotherapy response.

In this study we aimed to determine the ability of the apoptosomeassociated proteins APAF1, Pro-caspase 9, Pro-caspase 3, SMAC, and XIAP to serve as markers of survival in a cohort of Stage II and III colorectal cancer patients and in colorectal cancer patient response to 5-FU-based chemotherapy. Taken together, these studies indicate the potential clinical importance of Pro-Caspase 3 and APAF1 in the clinical setting, both in determining patient prognosis and in identifying effective treatment options.

\section{PATIENTS AND METHODS}

\section{Patient cohort}

Patients included in this study were drawn from a Phase III clinical trial of Stage II and III colorectal cancer patients comparing 5-FU/leucovorin adjuvant chemotherapy with postoperative observation (McDermott et al, 2003). Surgically resected tumours from patients $(n=224)$ were preserved as formalin-fixed paraffinembedded (FFPE) tissue for construction of tissue microarrays (TMAs). Clinicopathological details, including gender, age at surgery, histological stage, tumour grade, and TMN stage, were recorded for the study cohort (Table 1). Information regarding the randomisation of patients to chemotherapy or observation, time to and site of recurrence, as well as time to cancer-related mortality was available for this study. Median clinical follow-up time for this patient cohort was 73 months. This study has full ethical approval from local ethics committees involved in the study, with patients giving informed consent for use of tissue for research according to the Declaration of Helsinki.

\section{Tissue microarray construction and staining}

Tissue microarrays of the patient cohort were constructed as previously described (McLornan et al, 2010). Briefly, where possible up to four tumour cores were obtained from each patient using the Beecher Instruments arrayer (Sun Prairie, WI, USA) and placed into a paraffin block. Sections $4 \mu \mathrm{m}$ in thickness were cut, floated onto adhesive slides and baked overnight at $55^{\circ} \mathrm{C}$. Arrays were constructed at a density of 90-110 cores per array.

Table I Clincopathological characteristics

\begin{tabular}{|c|c|c|c|}
\hline & $\begin{array}{c}\text { Total } \\
(n=224)\end{array}$ & $\begin{array}{c}\text { 5-FU/leucovorin } \\
(n=I \mid 2)\end{array}$ & $\begin{array}{l}\text { No chemotherapy } \\
(n=|1| 2)\end{array}$ \\
\hline \multicolumn{4}{|l|}{ Gender } \\
\hline Male & 132 & 63 & 69 \\
\hline Female & 92 & 49 & 43 \\
\hline Age (median) & 64.1 & 66 & 65 \\
\hline \multicolumn{4}{|l|}{ Disease stage } \\
\hline Stage ॥ & 144 & 71 & 73 \\
\hline Stage III & 80 & 41 & 39 \\
\hline \multicolumn{4}{|l|}{ Tumour location } \\
\hline Ascending colon & 70 & 37 & 33 \\
\hline Transverse colon & 15 & 9 & 6 \\
\hline Decending colon & 88 & 40 & 48 \\
\hline Rectum & 48 & 23 & 25 \\
\hline Synchrous & 3 & 3 & 0 \\
\hline
\end{tabular}

Abbreviation: 5-FU = 5-fluorouracil.
For staining, antibodies were chosen based on their suitability for use on FFPE tissue and optimised with appropriate antigenretrieval methods and antibody dilutions (Supplementary Table 1). All staining was performed on a BondMax automated immunostainer (Leica Microsystems, Wetzlar, Germany). Briefly following dewaxing and appropriate antigen retrieval, the diluted primary antibody was applied to the cores for $20 \mathrm{~min}$ and localisation of bound antibody was performed using the Bond Polymer Refine DAB Kit (Leica Microsystems). Visualisation was performed using the enhanced diaminobenzidine tetrachloride with Harris' haematoxylin as counterstain. Positive and negative controls were constructed according to the suppliers' recommendations.

\section{Immunohistochemical scoring}

Following staining, tissue cores were scored according to quantity and intensity for APAF1, Pro-caspases 9 and 3, SMAC, and XIAP. Quantity and intensity scoring was according to a standardised scoring system, with quantity scores varying on a scale from 0 to 4 based on the percentage of cells staining positive and intensity scores ranging between 0 and 3. Scoring was carried out by two trained pathologists blinded to the clinical details and recorded, with discordant scores agreed by consensus. As multiple cores for each patient were arrayed, median intensity scores were used for all subsequent statistical analysis.

\section{Statistical analysis}

Cox proportional hazard analysis for recurrence-free and overall survival were carried out using SAS (SAS Institute Inc., Cary, NC, USA). Data were analysed separately for Stage II and Stage III disease with respect to both the sum and product values of the quantity and intensity scores, as well as individual quantity and intensity scores. The ability of each protein to function as a marker for chemotherapy response was assessed using survival analysis comparing those patients receiving 5-FU chemotherapy and those in the observation group. For all multivariate Cox regression analyses, in addition to median protein intensity, co-variates included in the model were gender, age, treatment, tumour stage, and tumour grade.

For generation of Kaplan-Meier survival curves for APAF1, SMAC, Pro-caspase 3 and Pro-caspase 9, patients were grouped as either 'strong staining' or 'weak staining' based on each protein's median intensity values across all patients. Specifically, intensity values for APAF1, Pro-caspase 3, and SMAC median-staining intensity $>2$, and $\geqslant 2$ for Pro-caspase 9 , were considered strong staining. Because of the strong staining patterns observed for XIAP in the majority of patients, the median intensity value was 3 (on a scoring scale of $0-3$ ); therefore a cutoff value of $\geqslant 2$ was used as this was the threshold intensity that was best able to dichomtomise patients. Intensity values less than these thresholds were considered 'weak staining'. Kaplan-Meier survival plots and logrank P-values for individual proteins and combinations were generated using SPSS PASW Statistics 18.0 (IBM SPSS Statistics, Somers, NY, USA), with $P$-values $<0.05$ considered to be significant.

\section{RESULTS}

\section{Clinicopathological details of patient cohort}

Tissue microarrays were constructed from tissue cores from chemonaive surgical resections from 224 Stage II and III colorectal cancer patients participating in a Phase III trial of adjuvant 5-FU/ leucovorin $v s$ observation alone (McDermott et al, 2003). The clinicopathological features of the patient cohort are indicated in Table 1. Patients were evenly randomised to either the 
chemotherapy or the observation group, with age, gender, tumour location, and disease stage being similar between the two arms of the study. Patients with Stage III disease had worse recurrence-free and overall survival than those with Stage II disease (log-rank test; $P<0.01$ for both, Supplementary Figure 1A and B). Comparing patients receiving chemotherapy $v s$ those randomised to the observation group, there was no significant difference in recurrence-free or overall survival between the two groups (Supplementary Figure 1C and D). When the effects of chemotherapy were analysed for stage, those with Stage II disease had no survival benefit from chemotherapy; however, there was a trend towards better survival in those Stage III patients receiving chemotherapy (Supplementary Figure 1E and F).

\section{Pro-caspase 3 and APAF1 act as potential prognostic} markers in Stage II and III colorectal cancer, respectively

In order to assess the ability of the key proteins involved in apoptosome-dependent caspase activation, that is, APAF1, Procaspases 9 and 3, XIAP and SMAC, to act as predictive markers for Stage II and III colorectal cancer, TMAs were stained and scored for quantity and intensity by a trained pathologist. Figure 1 depicts representative weak and strong staining in tumour tissue for each protein.

Traditionally, statistical analysis of immunohistochemical studies takes into account both quantity and intensity scores, specifically either their sum or their product. We therefore carried out a Cox proportional hazard analysis for both the sum and the product of the quantity and intensity scores. These univariate analyses indicated that when intensity scores were combined, no protein had prognostic value in our cohort of patients (Supplementary Tables 2 and 3). When the same analysis was carried out using either quantity or intensity scores individually, quantity scores showed similar results to that of the sum and product analyses, with no prognostic value being shown for any proteins. Surprisingly, when only intensity scores were analysed, the data indicated some potential prognostic capabilities for specific proteins (Tables 2 and 3). Therefore, subsequent analyses presented here were done using only intensity scores.

Apoptosome-dependent caspase activation staining was present in $97 \%$ of patients, with the majority of the patients $(60.2 \%)$ showing weak staining. In node-negative Stage II disease, there was no significant difference in Kaplan-Meier survival plots between strong and weak APAF1 staining for either recurrence-free (Figure 2A) or overall survival (Figure 2B). However, in Stage III disease, in which there is lymphatic involvement, patients with strong staining for the pro-apoptotic APAF1 had better recurrence-free $(P=0.046$; Figure $2 \mathrm{~A})$ and overall $(P=0.033$; Figure $2 \mathrm{~B})$ survival. While survival curves indicated that strong staining was indicative of better survival, Cox proportional hazard analysis of Stage III disease did not reflect this, with univariate hazard ratios (HR) of $0.918(P=0.5538)$ and $0.845(P=0.2251)$ for recurrencefree and overall survival, respectively (Tables 2 and 3 ).

Similarly to APAF1 expression, Pro-caspase 3 protein was expressed in the majority (87\%) of patients, with the majority (74\%) having weak tumour staining. Survival curves indicated that in Stage II, but not Stage III disease, patients with strong staining had better recurrence-free (Figure 2C) and overall (Figure 2D) survival than those with weak staining. This is reflected in the univariate Cox proportional hazard analysis, with hazard ratios of
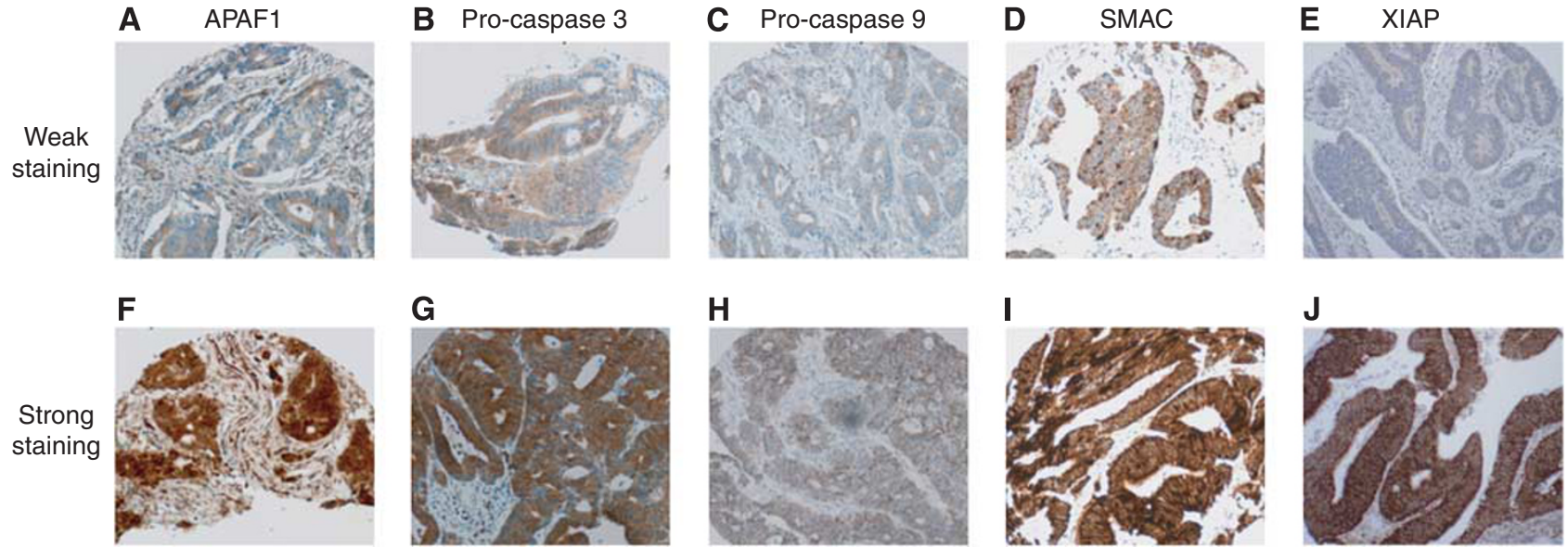

Figure I Representative images of weak and strong intensity staining for APAFI (A, F), Pro-caspase 9 (B, G), Pro-caspase 3 (C, H), SMAC (D, I), and XIAP $(\mathbf{E}, \mathbf{J})$ in colorectal tumours.

Table 2 Cox proportional hazard analysis for recurrence-free survival

\begin{tabular}{|c|c|c|c|c|c|c|c|c|}
\hline \multirow{2}{*}{ Protein } & \multicolumn{4}{|c|}{ Stage II } & \multicolumn{4}{|c|}{ Stage III } \\
\hline & \multicolumn{2}{|c|}{ Univariate } & \multicolumn{2}{|c|}{ Multivariate } & \multicolumn{2}{|c|}{ Univariate } & \multicolumn{2}{|c|}{ Multivariate } \\
\hline APAFI & $0.916(0.632-1.327)$ & 0.6413 & $0.886(0.610-1.288)$ & 0.5265 & $0.918(0.692-1.218)$ & 0.5538 & $0.883(0.657-1.187)$ & 0.4104 \\
\hline Pro-caspase 9 & $1.009(0.693-1.47 \mid)$ & 0.9616 & $1.001(0.685-1.463)$ & 0.9947 & $1.048(0.790-1.389)$ & 0.7467 & $1.125(0.838-1.511)$ & 0.4322 \\
\hline
\end{tabular}

Abbreviation: $\mathrm{Cl}=$ confidence interval. Bold values indicate $P<0.05$. 
Table 3 Cox proportional hazard analysis for overall free survival

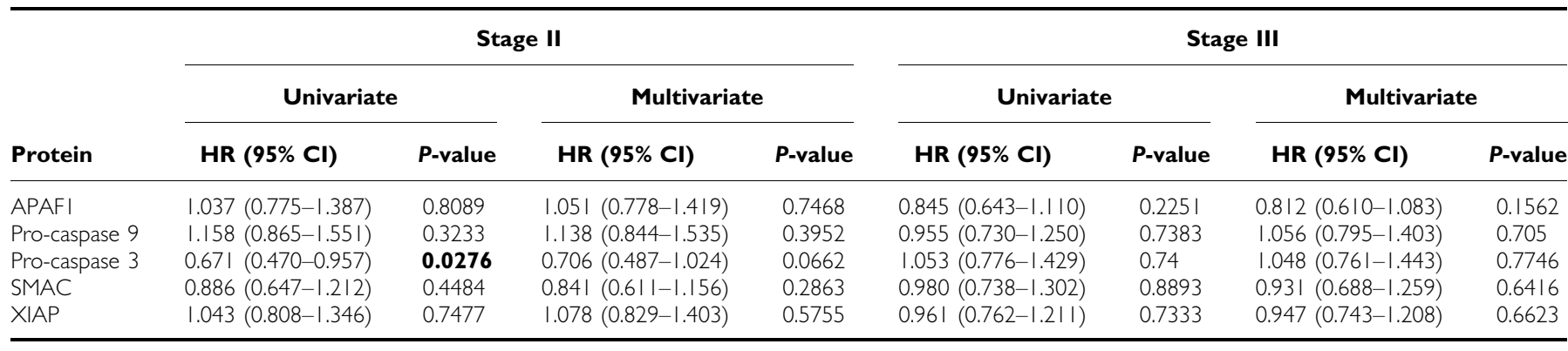

Abbreviation: $\mathrm{Cl}=$ confidence interval. Bold value indicates $P<0.05$.

A
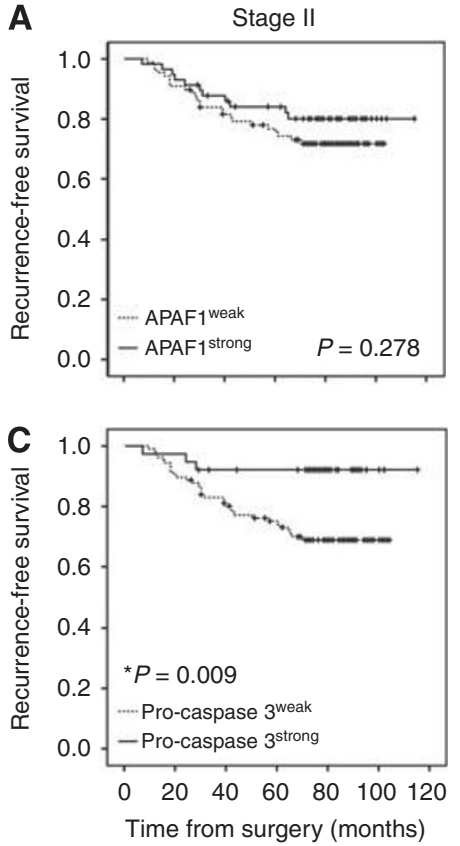
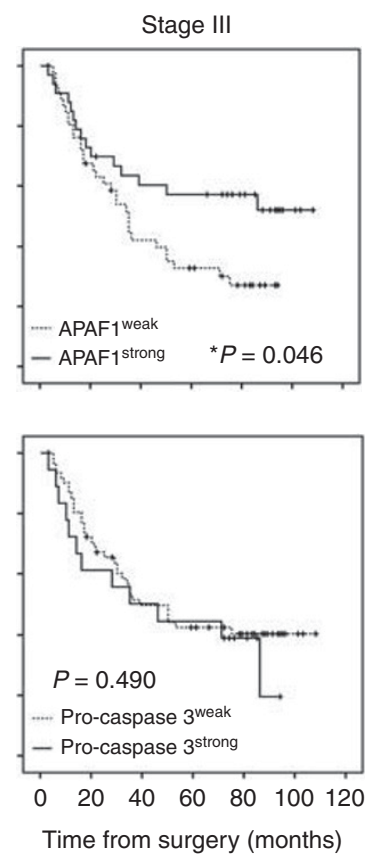

B
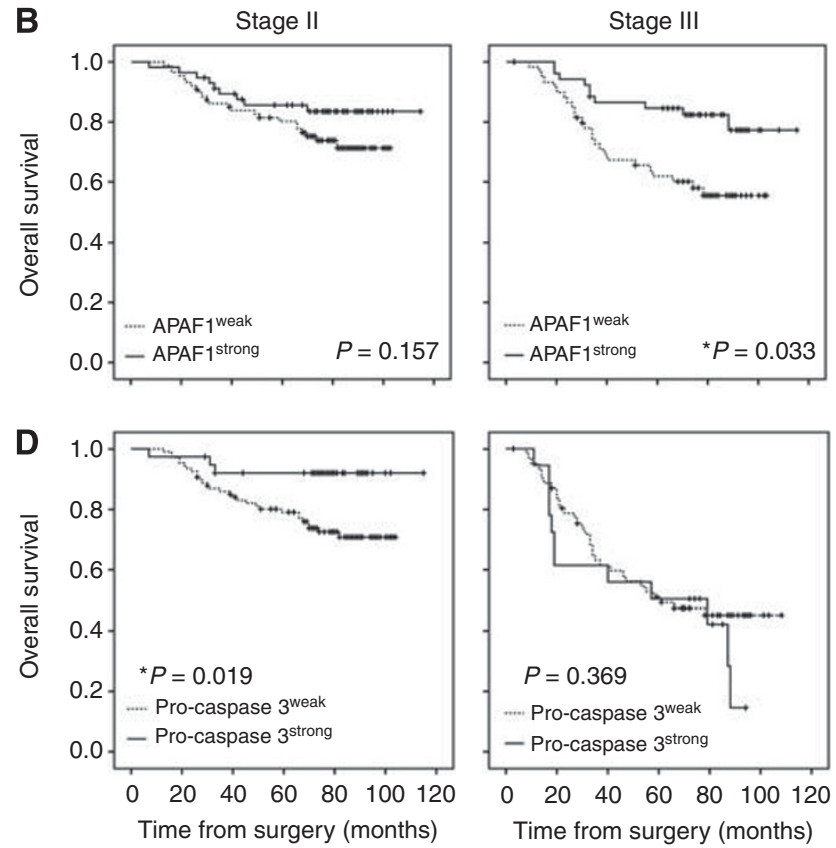

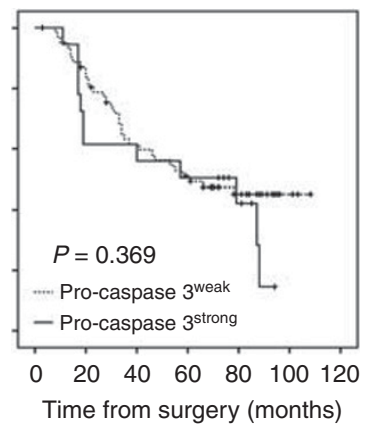

Figure 2 Apoptosome-associated proteins as single proteins and specific protein combinations are good predictors of recurrence-free and overall survival in Stage II and III colorectal cancer. Graphs depict recurrence-free (A, C) and overall (B, D) Kaplan-Meier survival plots for the single proteins APAFI (A, B) and Pro-caspase 3 (C, D) in Stage II (left panels) and Stage III (right panels) disease. Log-rank P-values are indicated.

0.495 (RFS; $P=0.0047$ ) and 0.671 (OS; $P=0.0276$ ) in Stage II disease compared to 1.076 (RFS; $P=0.6467$ ) and 1.053 (OS; $P=0.74$ ) in Stage III disease (Tables 2 and 3), indicating a strong predictive value for Pro-caspase 3 in Stage II colorectal cancer.

Examination of the other proteins, Pro-caspase 9, XIAP and SMAC, revealed no difference in the survival between weak and strong staining for either disease-free or overall survival (Supplementary Figures 2 and 3). Likewise, hazard ratios indicated no predictive capacity for these proteins in this patient cohort at the level of either recurrence-free or overall survival (Tables 2 and 3). Interestingly, XIAP staining, although not associated with patient outcome, was more strongly expressed in patients with more advanced disease, with $96 \%$ of Stage III patients exhibiting strong intensity XIAP staining (Supplementary Figures 2C and 3C) compared to $83 \%$ of Stage II tumours.

\section{Pro-caspase 3 is an independent prognostic marker in Stage II colorectal cancer}

In order to determine the influence of clinicopathological features on prognosis, multivariate Cox proportional hazard analysis was carried out for recurrence-free and overall survival, with gender, age, treatment, tumour stage, and tumour grade included as covariates. In all analyses, tumour stage consistently was identified as a significant covariate in both Stage II and Stage III disease. In Stage II disease, only strong Pro-caspase 3 expression was associated with better recurrence-free $(\mathrm{HR}=0.488)$ and overall survival $(\mathrm{HR}=0.706)$; however, this was significant in predicting recurrence $(P=0.0052)$ and approached significance for overall survival $(P=0.0662)$ (Tables 2 and 3$)$, indicating that Pro-caspase 3 may be an important independent prognostic marker in Stage II colorectal cancer. None of the other individual proteins examined were found to be associated with either recurrence-free or overall survival in multivariate analysis (Tables 2 and 3). Chemotherapy and tumour grade were significantly associated with longer and shorter overall survival, respectively, indicating their potential importance as prognostic markers in later disease stages.

\section{APAF1 expression predicts response to 5FU-based adjuvant chemotherapy}

Successful apoptosis execution is essential to the cell death induced by chemotherapeutics such as 5 -FU. Therefore, we next performed survival analysis to determine whether immunohistochemical expression of APAF1, Pro-caspase 3, Pro-caspase 9, SMAC, or XIAP were associated with clinical response in patients 
who received 5-FU-based chemotherapy. Interestingly, as individual proteins only APAF1 was able to predict patient response to 5-FU-based chemotherapy. Figure 3 shows the Kaplan-Meier survival curves for APAF1 when patients were stratified according to treatment arm. In those receiving 5-FU-based therapy, patients with strong APAF1 staining had better survival (Figure 3A and C), while there was no difference in survival plots in the observation arm of the study (Figure $3 \mathrm{~B}$ and $\mathrm{D}$ ). Hazard ratios for both recurrence-free $(\mathrm{HR}=0.27 ; \quad P=0.037)$ and overall survival $(\mathrm{HR}=0.350 ; P=0.006)$ in the chemotherapy arm of the study indicated that increasing expression of APAF1 is a strong positive predictor for response to 5-FU-based chemotherapy. Owing to the relatively small number of patients in each group, stages were combined at this point in order to perform more robust statistics.

\section{DISCUSSION}

Despite the ever-increasing insight into the biological basis of colorectal cancer and the concomitant development of targeted therapies, tumour staging remains the key factor in assessing patient prognosis and classical cytotoxic drugs remain the mainstay of adjuvant chemotherapies. On this note we assessed the immunohistochemical expression of critical apoptosis-regulating proteins (APAF1, Pro-caspases 9 and 3, SMAC and XIAP) and determined associations between expression and clinical outcome in a Stage II and III colorectal cancer patient cohort. While previous studies have shown that these proteins are differentially expressed in colorectal tumour tissue compared to normal tissue (Palmerini et al, 2001; Krajewska et al, 2005; Putt et al, 2006; Zlobec et al, 2006; Endo et al, 2009; Xiang et al, 2009), associations between protein expression and survival have not always been drawn. In this study we took a systematic approach and showed that Pro-caspase 3 expression in colorectal tumours is associated with better recurrence-free and overall survival, and serves as an independent prognostic marker in localised Stage II disease. This result is in agreement with previous studies that demonstrated caspase 3 expression to be a positive prognostic marker in hepatocellular carcinoma (Huang et al, 2010) and diffuse large B-cell lymphoma (Provencio et al, 2010).

The XIAP expression has been previously shown to be linked to metastasis and tumour aggressiveness in other solid tumours (Kluger et al, 2007; Shi et al, 2008; Gu et al, 2010). Interestingly, we observed XIAP to be strongly expressed in Stage III colorectal cancer, with weak staining in only $4 \%$ tumours compared to $17 \%$ in Stage II patients. We also observed that in Stage III disease, fewer patients exhibit strong Pro-caspase 3 staining compared to Stage II disease, suggesting that Pro-caspase 3 protein may be lost in colorectal cancer progression. Taken together, these findings indicate the concomitant loss of Pro-caspase 3 expression and increased expression of the anti-apoptotic XIAP may contribute to the decrease in apoptosis observed with advancing disease stage (Bedi et al, 1995).

In line with its function as a key protein for initiating caspase activation, we also demonstrate here that APAF1 expression is significantly associated with better survival in Stage III disease.
A
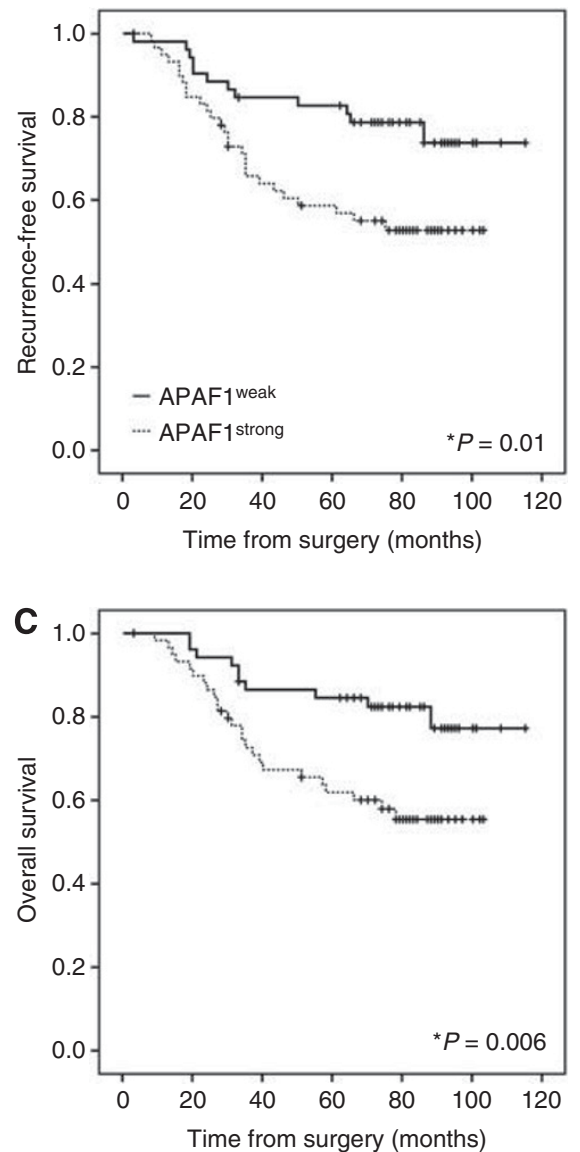

B
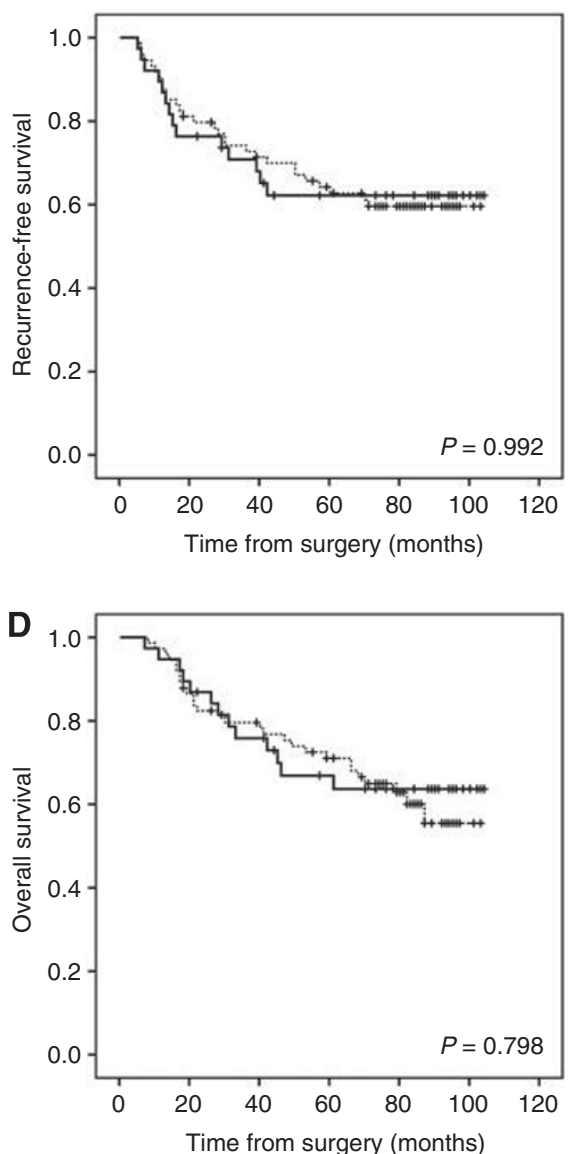

Figure 3 APAFI expression is associated with better survival in patients receiving 5-FU adjuvant chemotherapy. Graphs depict Kaplan-Meier recurrencefree $(\mathbf{A}, \mathbf{B})$ and overall $(\mathbf{C}, \mathbf{D})$ survival in patients receiving chemotherapy $(\mathbf{A}, \mathbf{C})$ and those in the observation group $(\mathbf{B}, \mathbf{D})$. Broken and solid lines represent patients with strong and weak staining for individual proteins, respectively. Log-rank P-values are indicated. 
Loss of APAF1 expression has previously been linked to tumour progression and more aggressive disease (Paik et al, 2007). We have similarly observed that in Stage II and III disease the majority of this patient cohort have weak immunohistochemical APAF1 staining. A previous study of Stage II colorectal cancer reported that APAF1 expression was similarly associated with better prognosis (Krajewska et al, 2005); however, this did not reach statistical significance. Importantly, one of the key findings of our study is the identification of an apparent 'switch' from a dependence on a loss of Pro-caspase-3 expression to a loss of APAF-1 expression during tumour progression. This may result from differential transcription factor binding to the respective promoters due to activation or inactivation of such factors during tumour progression. Similarly, it may be due to the fact that XIAP expression is increased in Stage III tumours, resulting in a more pronounced role for loss of APAF-1 expression owing to the ability of XIAP to neutralise caspase-3 but not APAF-1.

An important finding of our study is that APAF1 may have an important role in chemotherapy response and drug resistance in colorectal cancer, with APAF1 protein expression being the only individual protein whose expression was significantly associated with positive response to 5-FU-based treatment. As noted above, loss of APAF1 expression has previously been shown to identify with a more aggressive phenotype, which may also imply chemoresistance, although prior to this study none have shown APAF1 expression to be associated with chemotherapy response in colorectal cancer. Interestingly, a previous study also demonstrated that APAF1 positivity was a significant marker for complete tumour regression in rectal cancer patients who received neoadjuvant radiotherapy (Zlobec et al, 2006). Expression of APAF1 protein has been shown to be under epigenetic control, with apaf1 gene hypermethylation having been shown to be associated with negative clinical outcome in a number of tumour types, including melanoma (Soengas et al, 2001), renal cell carcinoma (Christoph et al, 2006a), neuroblastoma (Grau et al, 2011), and bladder cancer (Christoph et al, 2006b). Further studies examining whether loss of APAF1 protein expression in colorectal tumours is due to epigenetic mechanisms and how this correlates with chemotherapy responsiveness are certainly needed, as this may identify alternative therapies, such as those that target methylation, which may be effectively used for APAF1-negative colorectal cancer patients. Our study indicates that APAF-1 may potentially become a clinicopathological tool that facilitates the identification of colorectal cancer patients not responding to 5-FUbased chemotherapy.

Immunohistochemical studies aimed at determining a protein's value as either a prognostic or predictive marker will generally use a composite staining score which takes into account both the quantity and intensity scores (Harvey et al, 1999; Krajewska et al, 2005). An unexpected finding of this study is that for the proteins examined here, product or sum-derived composite score indicated no prognostic potential. Further analysis of intensity scores alone, however, demonstrated that for these proteins the intensity score alone was more informative than when quantity and intensity scores were combined into one score. Other studies have also shown that either quantity or intensity scores of certain proteins are predictive of survival (McCawley et al, 2011; Sinicrope et al, 2008). Consequently, it is possible that combining the quantity and intensity scores may mask any predictive capabilities of individual proteins, and that for Pro-caspase 3 and APAF1 the percentage of cells staining positive is not as important as the abundance of the protein within those positively staining cells. In future studies, it is therefore important that except for proteins such as Her2 in which the method of scoring is well-established, rigorous examination of the best-scoring method is necessary such that important information regarding potential markers is not lost.

In conclusion, the systematic approach conducted in our investigation identified for the first time an association between Pro-caspase 3 and survival in Stage II disease, thereby highlighting the possible importance this protein may have in identifying those patients who may benefit from adjuvant chemotherapy. Furthermore this study highlights the importance of APAF1 as a prognostic marker for Stage III colorectal cancer, but also as a marker for chemotherapy response.

\section{ACKNOWLEDGEMENTS}

This research was generously supported by a grant from the Health Research Board (APOCOLON; TRA/2007/26).

Supplementary Information accompanies the paper on British Journal of Cancer website http://www.nature.com/bjc

\section{REFERENCES}

Arango D, Wilson AJ, Shi Q, Corner GA, Aranes MJ, Nicholas C, Lesser M, Mariadason JM, Augenlicht LH (2004) Molecular mechanisms of action and prediction of response to oxaliplatin in colorectal cancer cells Br J Cancer 91(11): 1931-1946

Bedi A, Pasricha PJ, Akhtar AJ, Barber JP, Bedi GC, Giardiello FM, Zehnbauer BA, Hamilton SR, Jones RJ (1995) Inhibition of Apoptosis during Development of Colorectal Cancer. Cancer Res 55(9): 1811-1816

Center MM, Jemal A, Smith RA, Ward E (2009) Worldwide variations in colorectal cancer. CA Cancer J Clin 59(6): 366-378

Christoph F, Weikert S, Kempkensteffen C, Krause H, Schostak M, Köllermann J, Miller K, Schrader M (2006a) Promoter hypermethylation profile of kidney cancer with new proapoptotic p53 target genes and clinical implications. Clin Can Res 12(17): 5040-5046

Christoph F, Weikert S, Kempkensteffen C, Krause H, Schostak M, Miller K, Schrader M (2006b) Regularly methylated novel pro-apoptotic genes associated with recurrence in transitional cell carcinoma of the bladder. Int J Cancer 119(6): 1396-1402

de Gramont A, Figer A, Seymour M, Homerin M, Hmissi A, Cassidy J, Boni C, Cortes-Funes H, Cervantes A, Freyer G, Papamichael D, Le Bail N, Louvet C, Hendler D, de Braud F, Wilson C, Morvan F, Bonetti A (2000) Leucovorin and fluorouracil with or without oxaliplatin as first-line treatment in advanced colorectal cancer. J Clin Oncol 18(16): 2938-2947

De Oliveira Lima F, De Oliveira Costa H, Barrezueta LF, Fujiyama Oshima CT, Silva Jr. JA, Gomes TS, Pinheiro Jr. N, Neto RA, Franco M (2009)
Immunoexpression of inhibitors of apoptosis proteins and their antagonist SMAC/DIABLO in colorectal carcinoma: correlation with apoptotic index, cellular proliferation and prognosis. Oncol Rep 22(2): 295-303

Deveraux QL, Reed JC (1999) IAP family proteins-suppressors of apoptosis. Genes Dev 13(3): 239-252

Endo K, Kohnoe S, Watanabe A, Tashiro H, Sakata H, Morita M, Kakeji Y, Maehara Y (2009) Clinical significance of Smac/DIABLO expression in colorectal cancer. Oncol Rep 21(2): 351-355

Goldberg RM, Sargent DJ, Morton RF, Fuchs CS, Ramanathan RK, Williamson SK, Findlay BP, Pitot HC, Alberts SR (2004) A randomized controlled trial of fluorouracil plus leucovorin, irinotecan, and oxaliplatin combinations in patients with previously untreated metastatic colorectal cancer. J Clin Oncol 22(1): 23-30

Gourdier I, Del Rio M, Crabbé L, Candeil L, Copois V, Ychou M, Auffray C, Martineau P, Mechti N, Pommier Y, Pau B (2002) Drug specific resistance to oxaliplatin is associated with apoptosis defect in a cellular model of colon carcinoma. FEBS Lett 529(2-3): 232-236

Grau E, Martinez F, Orellana C, Canete A, Yañez Y, Oltra S, Noguera R, Hernandez M, Bermúdez JD, Castel V (2011) Hypermethylation of apoptotic genes as independent prognostic factor in neuroblastoma disease. Mol Carcinog 50(3): 153-162

Gray R, Barnwell J, McConkey C, Hills RK, Williams NS, Kerr DJ (2007) Adjuvant chemotherapy versus observation in patients with colorectal cancer: a randomised study. Lancet 370(9604): 2020-2029 
Gu LQ, Li FY, Zhao L, Liu Y, Chu Q, Zang XX, Liu JM, Ning G, Zhao YJ (2010) Association of XIAP and P2 $\times 7$ receptor expression with lymph node metastasis in papillary thyroid carcinoma. Endocrine 38(2): 276-282

Harvey JM, Clark GM, Osborne CK, Allred DC (1999) Estrogen Receptor Status by Immunohistochemistry Is Superior to the Ligand-Binding Assay for Predicting Response to Adjuvant Endocrine Therapy in Breast Cancer. J Clin Oncol 17(5): 1474-1481

Hector S, Prehn JH (2009) Apoptosis signaling proteins as prognostic biomarkers in colorectal cancer: a review. Biochim Biophys Acta 1795(2): 117-129

Huang H, Zhang XF, Zhou HJ, Xue YH, Dong QZ, Ye QH, Qin LX (2010) Expression and prognostic significance of osteopontin and caspase- 3 in hepatocellular carcinoma patients after curative resection. Cancer Sci 101(5): 1314-1319

Igney $\mathrm{FH}, \mathrm{Krammer} \mathrm{PH}$ (2002) Death and anti-death: tumour resistance to apoptosis. Nat Rev Cancer 2(4): 277-288

Jemal A, Bray F, Center MM, Ferlay J, Ward E, Forman D (2011) Global cancer statistics. CA: A Cancer J Clin 61(2): 69-90

Johnstone RW, Ruefli AA, Lowe SW (2002) Apoptosis: a link between cancer genetics and chemotherapy. Cell 108(2): 153-164

Kaufmann SH, Earnshaw WC (2000) Induction of apoptosis by cancer chemotherapy. Exp Cell Res 256(1): 42-49

Kluger HM, McCarthy MM, Alvero AB, Sznol M, Ariyan S, Camp RL Rimm DL, Mor G (2007) The X-linked inhibitor of apoptosis protein (XIAP) is up-regulated in metastatic melanoma, and XIAP cleavage by Phenoxodiol is associated with Carboplatin sensitization. J Transl Med 5: 6

Krajewska M, Kim H, Kim C, Kang H, Welsh K, Matsuzawa S-i Tsukamoto M, Thomas RG, Assa-Munt N, Piao Z, Suzuki KPerucho M, Krajewski S, Reed JC (2005) Analysis of apoptosis protein expression in early-stage colorectal cancer suggests opportunities for new prognostic biomarkers. Clin Cancer Res 11(15): 5451-5461

Li P, Nijhawan D, Budihardjo I, Srinivasula SM, Ahmad M, Alnemri ES, Wang X (1997) cytochrome $c$ and dATP-dependent formation of Apaf-1/ Caspase-9 complex initiates an apoptotic protease cascade. Cell 91(4): 479-489

MacFarlane M, Merrison W, Bratton SB, Cohen GM (2002) Proteasomemediated degradation of Smac during apoptosis: XIAP promotes Smac ubiquitination in vitro. J Biol Chem 277(39): 36611-36616

McCawley N, Conlon S, Hector S, Cummins RJ, Dicker P, Johnston PG, Kay EW, McNamara DA, Prehn JHM, Concannon CG (2011) Analyzing proteasomal subunit expression reveals Rpt4 as a prognostic marker in stage II colorectal cancer. Int J Cancer; e-pub ahead of print 29 September 2011; doi: 10.1002/ijc.26468

McDermott U, Boyd RE, Houston RF, Kee F, McAleer JJ, Millar J, McAdams T, Sloan JM, Moorehead RJ, Wilson RH (2003) A phase III trial of short duration adjuvant chemotherapy with bolus/infusional 5-fluorouracil (FU) and folinic acid (FA) versus surgery alone in dukes' $\mathrm{B}$ and $\mathrm{C}$ colorectal cancer (CRC). Proc Am Soc Clin Oncol 22: 1363
McLornan DP, Barrett HL, Cummins R, McDermott U, McDowell C, Conlon SJ, Coyle VM, Van Schaeybroeck S, Wilson R, Kay EW Longley DB, Johnston PG (2010) Prognostic significance of TRAIL signaling molecules in stage II and III colorectal cancer. Clin Cancer Res 16(13): 3442-3451

Paik SS, Jang KS, Song YS, Jang SH, Min KW, Han HX, Na W, Lee KH Choi D, Jang SJ (2007) Reduced expression of Apaf-1 in colorectal adenocarcinoma correlates with tumor progression and aggressive phenotype. Ann Surg Oncol 14(12): 3453-3459

Palmerini F, Devilard E, Jarry A, Birg F, Xerri L (2001) Caspase 7 downregulation as an immunohistochemical marker of colonic carcinoma. Human Pathol 32(5): 461-467

Provencio M, Martin P, Garcia V, Candia A, Sanchez AC, Bellas C (2010) Caspase 3a: new prognostic marker for diffuse large B-cell lymphoma in the rituximab era. Leuk Lymphoma 51(11): 2021-2030

Putt KS, Chen GW, Pearson JM, Sandhorst JS, Hoagland MS, Kwon JT, Hwang SK, Jin H, Churchwell MI, Cho MH, Doerge DR, Helferich WG, Hergenrother PJ (2006) Small-molecule activation of procaspase-3 to caspase-3 as a personalized anticancer strategy. Nat Chem Biol 2(10): 543-550

Shi YH, Ding WX, Zhou J, He JY, Xu Y, Gambotto AA, Rabinowich H, Fan J, Yin XM (2008) Expression of X-linked inhibitor-of-apoptosis protein in hepatocellular carcinoma promotes metastasis and tumor recurrence. Hepatology 48(2): 497-507

Sinicrope FA, Rego RL, Foster NR, Thibodeau SN, Alberts SR, Windschitl HE, Sargent DJ (2008) Proapoptotic Bad and Bid protein expression predict survival in stages II and III colon cancers. Clin Cancer Res 14(13): 4128-4133

Soengas MS, Capodieci P, Polsky D, Mora J, Esteller M, Opitz-Araya X, McCombie R, Herman JG, Gerald WL, Lazebnik YA, Cordon-Cardo C, Lowe SW (2001) Inactivation of the apoptosis effector Apaf-1 in malignant melanoma. Nature 409(6817): 207-211

Strater J, Herter I, Merkel G, Hinz U, Weitz J, Moller P (2010) Expression and prognostic significance of APAF-1, caspase- 8 and caspase- 9 in stage II/III colon carcinoma: caspase- 8 and caspase- 9 is associated with poor prognosis. Int J Cancer 127(4): 873-880

Suzuki Y, Nakabayashi Y, Takahashi R (2001) Ubiquitin-protein ligase activity of $\mathrm{X}$-linked inhibitor of apoptosis protein promotes proteasomal degradation of caspase- 3 and enhances its anti-apoptotic effect in Fas-induced cell death. Proc Natl Acad Sci 98(15): 8662-8667

Verhagen AM, Ekert PG, Pakusch M, Silke J, Connolly LM, Reid GE, Moritz RL, Simpson RJ, Vaux DL (2000) Identification of DIABLO, a mammalian protein that promotes apoptosis by binding to and antagonizing IAP proteins. Cell 102(1): 43-53

Xiang G, Wen X, Wang H, Chen K, Liu H (2009) Expression of X-linked inhibitor of apoptosis protein in human colorectal cancer and its correlation with prognosis. J Surg Oncol 100(8): 708-712

Zlobec I, Vuong T, Compton CC (2006) The predictive value of apoptosis protease-activating factor 1 in rectal tumors treated with preoperative, high-dose-rate brachytherapy. Cancer 106(2): 284-286

This work is published under the standard license to publish agreement. After 12 months the work will become freely available and the license terms will switch to a Creative Commons Attribution-NonCommercial-Share Alike 3.0 Unported License. 